\title{
CLASIFICACIONES ORACIONALES SEGÚN LA MODALIDAD \\ (AMMON. IN INT. 2,9-3,6 Y 64,29-65,2)
}

Regla Fernández Garrido

1. El presente trabajo constituye una aproximación a un aspecto de teoría lingüística antigua: la clasificación oracional según la modalidad de frase. El texto que nos servirá de punto de partida es Int. 17a2-4:

"Pero declarativo no es todo (sc. enunciado), sino en el que se da el decir verdad o mentira. Y no se da en todos, por ejemplo la súplica es un enunciado, pero no es verdadero ni falso"1.

En este pasaje está sólo esbozada la idea de la modalidad oracional y se distingue someramente entre el enunciado lógico, el declarativo, y los demás enunciados, como la súplica. Todos ellos comparten el hecho de significar algo. Aristóteles, no obstante, dice que sólo el enunciado declarativo puede significar algo verdadero o falso. Esta afirmación se explica porque se está hablando desde un punto de vista filosófico, según el cual sólo la declaración, constituida por un sujeto y un verbo en tercera persona que predica del sujeto, juega un papel en la lógica. Sin embargo, si hablamos en un sentido más general, podemos afirmar que también los demás tipos de oración pueden expresar algo verdadero o falso ${ }^{2}$.

Con objeto de la exégesis de este pasaje aristotélico, Ammonio expone una clasificación oracional desde el punto de vista peripatético, pero los textos en que realmente nos vamos a basar se hallan en las páginas iniciales de su comentario in de Interpretatione ${ }^{3}$ y reproducen dos clasificaciones oracionales, una desde la perspectiva peripatética y otra desde la estoica.

2. Según el Perípato, afirma Ammonio en su comentario al de Interpretatione, existen cinco tipos diferentes de enunciado:

"A continuación, según lo definido al principio, pasa al estudio del enunciado declarativo, del que decíamos que es una especie del enunciado simple, como lo

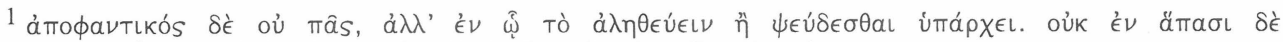

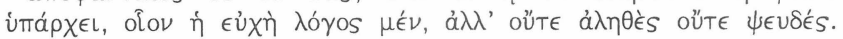

${ }^{2}$ En este sentido apunta J.R. Searle, que afirma que todos los actos de habla ("speech acts") tienen en común el hacer referencia a algo y la predicación: "the same reference and predication can occur in the performance of different complete speech acts" (Speech Acts, Cambridge, 1969, p.23).

${ }^{3}$ Edición de A. Busse (1897) CAG 4.5.
} 
son el apelativo, el deprecativo, el interrogativo y el imperativo, cada uno de los cuales es completo y significativo por sí mismo de un pensamiento completo. Porque del mismo modo que "el alma es inmortal" muestra algo, así también (muestran algo) "ijueces!", "¡Ojalá fuera yo filósofo!", "¿Cuándo has venido?" y "¡Vuélvete a éste!"4.

Es evidente que Ammonio está hablando de tipos de oración y no de modos verbales, como se desprende de la terminología ("especie del enunciado simple") y de los ejemplos que ilustran el pasaje.

Por consiguiente, ya podemos ir adelantando conclusiones: lo que establece este autor (y en general las fuentes antiguas) son clasificaciones oracionales y parecen, por tanto, hacer referencia a la modalidad y no a los modos verbales. Es importante esta puntualización porque se justifica así que en este trabajo omitamos toda referencia al modo verbal. La modalidad es una categoría que afecta a la oración en su totalidad, frente al modo, categoría morfosintáctica del verbo.

Estos tipos oracionales que menciona el comentarista están directamente relacionados con las dos clases de facultades que operan en el alma humana: las cognitivas y las vitales, también llamadas apetitivas ${ }^{5}$. En virtud de las cognitivas conocemos las diferentes realidades y en virtud de las apetitivas, las apetecemos. El enunciado declarativo es producto de las facultades cognitivas y los demás tipos de oración, de las apetitivas. El alma es capaz de conocer por sí misma, pero no de satisfacer su apetito. Necesita pues, de alguien que sacie su deseo. Éste puede consistir en una palabra o palabras que satisfagan su curiosidad (para ello se sirve de la interrogación) o en una determinada acción. En este caso, puede ocurrir que pretenda tener acceso a la persona a quien va dirigido el enunciado, por lo que la interpela (enunciado apelativo), o que desee que esta persona realice para ella una determinada acción. Si se encuentra ante esta posibilidad, puede suceder que esta persona de la que pretende algo sea un alguien superior, por lo que se dirige a ella de un modo determinado (enunciado deprecativo) o que sea un inferior y el modo de elocución es diferente (enunciado imperativo $)^{6}$. A propósito de este pasaje, D.M. Schenkeveld ${ }^{7}$ afirma que es el primer testimonio de una teoría acerca de la existencia de dos facultades anímicas que producen los

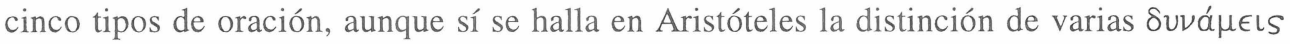

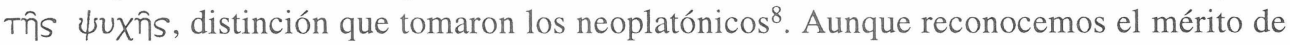
este autor en intentar establecer las fuentes de las clasificaciones oracionales - tanto la

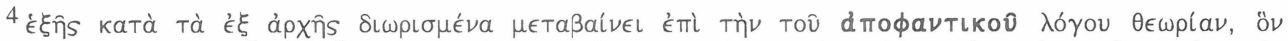

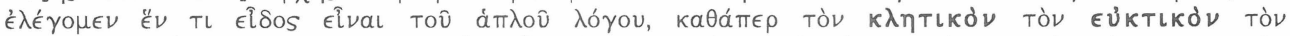

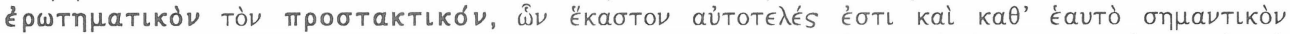

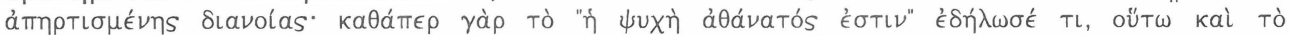

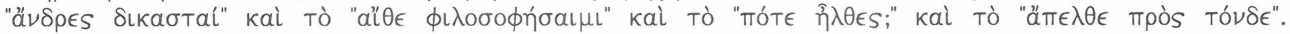
(64,29-65,2. Cf. et. 2,9-21.)

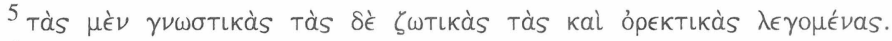

6 5,1-17.

7 "Studies in the History of Ancient Linguistics II: Stoic and Peripatetic Kinds of Speech Acts and the Distinction of Grammatical Moods". Mnemosyne 37, fasc. 3-4, 1984, p. 298.

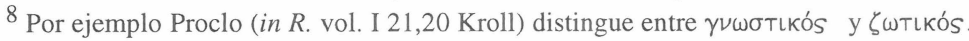


peripatética como la estoica, a la que luego nos referiremos-, realiza sin embargo afirmaciones que resultan faltas de fundamento. Así, data la clasificación oracional desde la perspectiva peripatética en el s. V p.C., en torno al 450, aunque reconoce que en la época de Aristóteles debió prestarse atención a una clasificación de los distintos actos de habla9 Nosotros, por el contrario, pensamos que en el Estagirita pueden hallarse rastros que permiten reconstruir una teoría sobre la modalidad de frase y que aluden explícitamente a diferentes tipos oracionales. Además del texto del Int. mencionado al principio de este trabajo (Int. 17a2-4), podemos citar Po. 1456b8-13 y 1457a18-23. En el primer pasaje Aristóteles pone en estrecha relación la entonación (íтокрцтьки́ ) con los esquemas o formas de expresión ( $\sigma \chi \eta \dot{\mu} \mu a t a$ Tท̂S $\left.\lambda \epsilon^{\prime} \xi \epsilon \omega S\right)^{10}$. En la lista que ofrece de éstos y que no

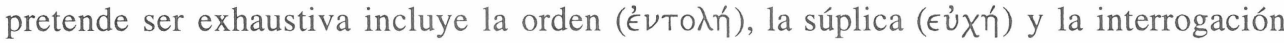

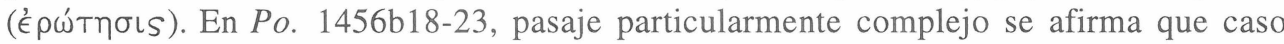
( $\pi T \omega \sigma(\iota)$, además de significar las nociones casuales en sentido estricto y el número, significa también lo relativo a la entonación (

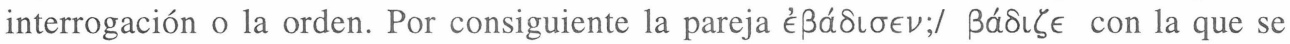
ilustra este pasaje ha de ser entendida no como formas verbales aisladas, sino como frases de un solo miembro en las que el contexto suple los elementos que faltan, por lo que el Estagirita estaría refiriéndose a la modalidad oracional, que estaría marcada por la entonación.

Además de estos textos en los que aparece una incipiente teoría sobre la modalidad, encontramos también en Aristóteles un fragmento que trata de las facultades anímicas y que

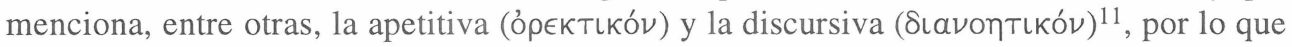
se aprecian huellas aristotélicas en el nacimiento de una teoría que adquiere su desarrollo máximo en Ammonio. Además de todo esto, otra razón para rechazar las tesis de Schenkeveld es que resulta un tanto incoherente situar el nacimiento de una teoría que se denomina peripatética en el s. V p.C.

Esta dicotomía entre dos tipos de facultades del alma humana tiene reflejo, si bien desde otra perspectiva, en estudios de investigadores actuales que se han ocupado de la modalidad. Entre éstos destaca F.R. Palmer, quien distingue dos tipos de modalidad, la epistémica ('epistemic') y la deóntica ('deontic'). La primera indica el compromiso del hablante con lo que dice y pueden distinguirse grados ${ }^{12}$. En ella se incluye la declaración. La modalidad deóntica está relacionada con la acción y sus realizaciones gramaticales más importantes son las 'directives' y las 'commissives'. El esquema bipartito de Palmer es, por lo tanto, básicamente el mismo que el de Ammonio, con la única salvedad de que para éste

\footnotetext{
${ }^{9}$ D.M. Schenkeveld, art. cit. p. 300.

${ }^{10} \mathrm{G}$. Nuchelmans afirma muy acertadamente que "this expression does not designate the figures of speech here, but Aristotle indicates by it certain ways in which the meaning of a phrase may be determinated by the speaker's intonation" (Theories of the Proposition. Ancient and Medieval Conceptions of the Bearers of Truth and Falsity, 1973, p.30)

${ }^{11}$ El texto es de An. 414a29-b2.

12 Por ejemplo en inglés existen tres tipos de juicios epistémicos: el verbo 'may' indicaría un juicio posible, 'will' un juicio razonable y 'must' el único juicio posible (F.R. Palmer, op. cit., p.57)
} 
la declaración no está marcada modalmente porque en ella no interviene la subjetividad, mientras que para Palmer la subjetividad es inherente a la modalidad.

Ya nos hemos referido anteriormente a que la clasificación oracional desde el punto de vista del Perípato que reproduce Ammonio se ve complementada con otra igual, pero desde la perspectiva estoica, clasificación que aumenta los tipos de oración hasta ocho ${ }^{13}$ :

"Los Estoicos llaman al enunciado declarativo (apophantikón) ${ }^{14}$ axioma 15; al deprecativo (euktikón), aratikón; al apelativo (kletikón), prosagoreutikón, añadiendo a éstos otros cinco tipos de enunciado que claramente pueden relacionarse con alguno de los ya mencionados. Pues dicen que existe el juramento (omotikón) como "Que la tierra sea testigo de esto", el enunciado expositivo (ekthetikón), por ejemplo "Sea ésta una línea recta", el hipotético (hypothetikón) como "Supóngase que la tierra sea el centro de la esfera solar", otro semejante al axioma, por ejemplo " Cómo florece el azar en la vida humana!". Todos estos, si aceptan lo de verdad y falsedad, podrían relacionarse con el declarativo, superando el juramento a la declaración por el testimonio de la divinidad, y el semejante al axioma por el añadido del adverbio intensivo hos .Y afirman que el quinto además de éstos es la interrogación dubitativa ${ }^{16}$ (epaporetikón), por ejemplo "Aquí está Daos, ¿qué va a anunciar?", que claramente es el mismo que el interrogativo, excepto en que coloca la prótasis antes de la pregunta"17.

Ammonio afirma que los estoicos designan de manera diferente a los peripatéticos al enunciado declarativo, al deprecativo y al interrogativo. Y que, dentro de la declaración, como si fueran subespecies de ésta, distinguen cuatro tipos, por lo que intenta explicar el juramento, la exposición, la hipótesis y el enunciado semejante al axioma como desarrollos a partir de la declaración. Esto es una prueba más de que el comentarista no establece clasificaciones modales, sino oracionales.

Cuando D.M. Schenkeveld se detiene para comentar este pasaje ammoniano nos vuelve a sorprender. Podría pensarse que por el orden del propio comentarista - que reproduce en primer lugar la clasificación peripatética y a continuación la estoica -, los tipos oracionales según el esquema del Perípato son anteriores cronológicamente a los tipos oracionales estoicos. Sin embargo Schenkeveld afirma que Ammonio se equivoca en este

$13 \mathrm{O}$, mejor dicho, hasta diez, si tenemos en cuenta que la omisión de los tipos mpoбтактıкóv y el

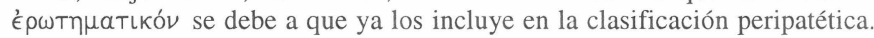

${ }^{14}$ En el texto griego aparecen adjetivos neutros singulares porque esta clasificación, al ser estoica, se refiere a lektá completos, que equivalen a los lógoi peripatéticos.

15 Transcribimos los términos para dejar claro que la clasificación oracional es esencialmente la misma y que sólo varía el nombre técnico de cada tipo oracional.

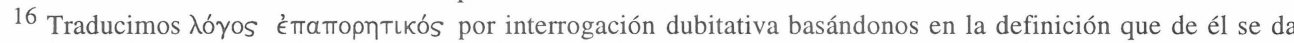
en las distintas clasificaciones. Ammonio lo caracteriza como un tipo de oración igual al interrogativo pero que no es el pronombre o adverbio interrogativo quien encabeza la pregunta. Plantea una duda que no exige ser solventada porque es una pregunta que se formula uno mismo a sí mismo ( $C f$. Theon Prog. 4. 88,9-17. Spengel). 17 2,26-3,6. 
punto, porque la clasificación oracional peripatética no surge hasta el s. V. p. C., mientras que la estoica ya existía, si no en el s. III a.C., sí en el s. I a.C., ya que la exposición de teoría lingüística y dialéctica estoica de Diógenes Laercio - la fuente principal para reconstruir esta teoría - se basa en el testimonio de Diocles, al que hay que situar en el s. I a. $C^{18}$. En nuestra opinión, todo esto puede ser entendido de una manera mucho más simple. La clasificación peripatética puede remontarse - si no a Aristóteles por toda su complejidad - a sus discípulos más inmediatos, comenzando por Teofrasto, del que Ammonio ofrece el testimonio de que distingue dos "modos de ser" ( $\sigma \chi \epsilon \in \sigma \in \mathrm{E} S$ ) del enunciado, uno con relación a las realidades y otro con relación al oyente ${ }^{19}$. No es necesario alterar la fecha de la ordenación estoica para mantener que la peripatética es anterior cronológicamente, por lo que el orden de Ammonio sería correcto.

El elenco peripatético no presenta problemas. Consta de cinco clases de enunciado que además de ser reproducidos por Ammonio, aparecen en otras fuentes ${ }^{20}$. Estos tipos son el

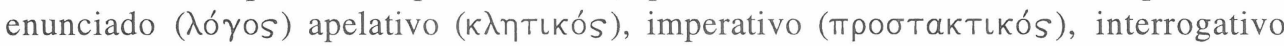

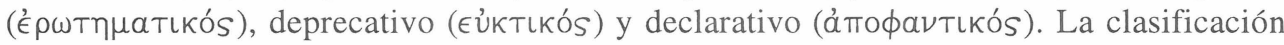
estoica es más compleja que la peripatética. En primer lugar, el número de términos que la componen varía de un autor a otro, oscilando entre cinco y once ${ }^{21}$. No obstante, la mayoría de los intérpretes coinciden en afirmar que la lista estoica se compone de diez elementos, que se corresponden exactamente con los que ofrece Diógenes Laercio recogiendo el testimonio

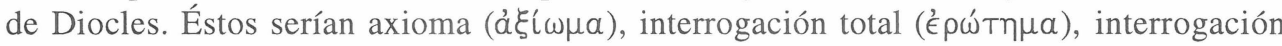

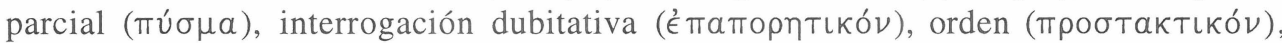
juramento (ỏ

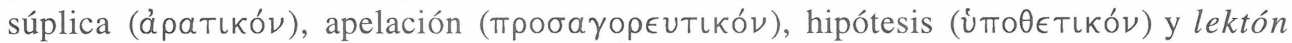

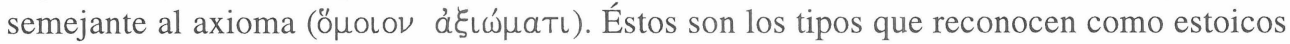
R. T. Schmidt ${ }^{22}$ y D. M. Schenkeveld ${ }^{23}$. Sin embargo, otros autores modifican

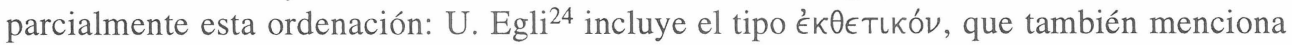

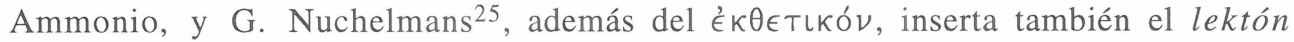

\footnotetext{
18 Vid. E. Wellmann "Diokles" 50), RE col. 798-801.

19 65,31-33. Cf. Thphr. fr. 65, p.431 Wimmer.
}

20 Anonymus Coislianus in Int. (p. XXII-XXIII. Busse), Prolegomena anónimos del De statibus de Hermógenes (186,17-187,2. Rabe) y Scholia in Aphthonium (661, 25-662,4. Walz). )

${ }^{21}$ Así, la clasificación de S.E. (M. VIII 70-74) consta de cinco miembros, la lista del léxico Suda (s.v. axioma, vol. I p.255 Adler = Die Fragmente zur Dialektik der Stoiker. Neue Sammlung der Texte mit deutscher Übersetzung und Kommentar, K. Hülser (ed.), Stuttgart, 1988) presenta ocho y las de Ammonio $(2,26-3,6)$ y Diógenes Laercio (VII 66-68), diez. Por último, de once términos se componen las clasificaciones del Anonymus Coisilianus in Int. (p. XXII-XXIII. Busse), de los Prolegomena anónimos del De statibus hermogeniano (186,17-188,5. Rabe) y de los Scholia in Aphthonium (662,5-26. Walz).

22 Stoicorum Grammatica, Halle,1839, p. 88. (Traducción alemana: Die Grammatik der Stoiker. Einführung, Übersetzung und Bearbeitung von K. Hülser, mit einer kommentierten Bibliographie zur stoischen Sprachwissenschaft [Dialektik] von U. Egli, Braunschweig/ Wiesbaden, 1979).

23 art. cit., p. 310.

${ }^{24}$ Zur stoischen Dialektik. Tesis doctoral. Basel, 1967, p.36. 


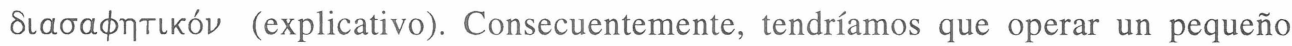
cambio en la lista que nos da nuestro comentarista, cambio que ya hemos sugerido antes: el

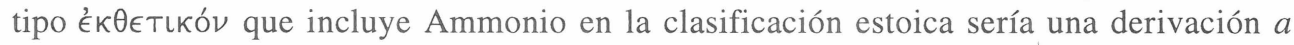

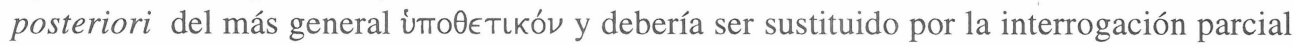
$(\pi \cup ́ \sigma \mu \alpha)$ a la que alude el comentarista en otros momentos de su obra ${ }^{26}$.

3. El criterio que sigue Ammonio en sus dos clasificaciones oracionales consiste en distinguir por un lado la declaración (y los tipos que pueden explicarse a partir de ella en el caso de la ordenación estoica) y los demás tipos de oración. Distingue, por tanto, dos grandes grupos, el primero tiene un papel en la lógica y el segundo no, en el primero no desempeña ningún papel la subjetividad y en el segundo sí.

Este principio de ordenación puede hallarse también en tendencias lingüísticas modernas. La lógica tradicional distingue entre una modalidad objetiva y otra subjetiva, con un enfoque muy parecido al del comentarista, según el cual en la declaración no interviene para nada la subjetividad, por lo que sería la no-modalidad, frente a los demás tipos, que sí estarían marcados modalmente. Sin embargo, algunos estudiosos modernos se oponen a esta interpretación y consideran que no puede hablarse de modalidad objetiva, porque la modalidad implica en sí misma la intervención de la subjetividad del hablante ${ }^{27}$.

Los autores modernos que se han ocupado de la modalidad no suelen hacer clasificaciones oracionales, como hemos visto en Ammonio, sino que prefieren hablar de "expresiones"28, de "actos de habla"29, sin ocuparse de las realizaciones gramaticales de éstos, que varían según las lenguas. Por ejemplo, cada lengua articula de una forma las oraciones interrogativas: o bien invirtiendo el sujeto, o bien utilizando partículas que las introducen, o bien por medio de la entonación, o incluso en algunas lenguas existe un medio formal que expresa la ignorancia que el hablante tiene sobre los hechos ${ }^{30}$. Distinguen nítidamente expresiones y oraciones ${ }^{31}$, distinción que no se halla en los autores antiguos.

Aunque en los estudios modernos no se habla de tipos oracionales, sí se halla en ellos el esquema bipartito del comentarista, con una diferenciación entre la declaración y los demás tipos. La corriente mayoritaria consiste en distinguir por un lado los actos por los que el hablante se limita a hacer una afirmación sobre la realidad y que pueden ser verdaderos o falsos y aquéllos que no implican una predicación, sino una acción. En este sentido

26 199,19-23 y 200,4-10.

27 Así F.R. Palmer (op. cit. p.16) define la modalidad como "the grammaticalization of speaker's (subjective) attitudes and opinions".

28 Como O. Jespersen (The Philosophy of Grammar, London, 1924, pp.302-303).

${ }^{29}$ El primero que utilizó explícitamente el término speech act fue J.L. Austin (Philosophical Papers, London y N. York, 1970 [1961])

${ }^{30}$ F.R. Palmer, op. cit. p.30-31.

31 Como por ejemplo J. Lyons, que diferencia entre utterances y statements. Al primer grupo asigna la aseveración (statement), la pregunta (question) y la orden (command) y al segundo la oración declarativa, la interrogativa y la imperativa (Semantics, Cambridge, 1977, p.745). 
apuntan las tesis de J.L. Austin ${ }^{32}$ y las de J.R. Searle ${ }^{33}$. Y cuando estos autores desarrollan con más detalle sus teorías siguen presentando puntos de contacto con la teoría antigua. Así, J.L. Austin distingue, en un trabajo posterior, tres tipos de actos: "locutionary", "illocutionary" y "perlocutionary"34. El primero consiste en decir algo significativo y correspondería a la oración declarativa del comentarista. El segundo es un acto que se realiza al decir algo: hacer una promesa, plantear una pregunta, y serían la interrogación, la súplica, el juramento y la hipótesis. El tercero es un acto que se realiza por medio de decir algo: persuadir a alguien para que haga algo, y en la clasificación de Ammonio estaría representado por la apelación y la orden.

4. La conclusión de todas estas páginas es que la modalidad es una categoría que se asocia a la oración en su conjunto y no sólo al verbo, como el modo. Es muy difícil definirla porque puede venir dada por varias marcas, además de jugar en ella un papel muy importante la subjetividad del hablante. La dicotomía tradicional entre modalidad objetiva y subjetiva, que es la que ofrece Ammonio, es superada por los autores actuales que defienden que en la modalidad juega un papel primordial la subjetividad del hablante. Por lo tanto, modalidad implica subjetividad. Esta idea la recoge repetidas veces F.R. Palmer, que afirma que la modalidad epistémica indica el grado de conocimiento del hablante de la realidad y que implica un compromiso de éste con lo que le rodea. Por lo tanto en esta modalidad, que es la más neutra y la más próxima a la declaración, es fundamental la actitud del hablante.

Ya hemos visto que una gran diferencia entre la clasificación antigua y las que ofrecen los modernos estriba en que la primera habla de oraciones y las segundas de actos de habla. Sin embargo, Ammonio en sus ejemplos supera el carácter estático que podría suponer una clasificación oracional e incluye el componente dinámico de la acción que implican los actos de habla. Para ilustrar sus tipos oracionales utiliza ejemplos que intentan recoger la fuerza del acto que les corresponde: "¡Jueces!", "¡Ojalá fuera yo filósofo!", etc.

32 Habla de "constantive and performatives utterances" (Philosophical Papers, London-N. York, 1970 [1961])

33 Que distingue entre "propositional act" y "illocutionary act" (Speech Acts, Cambridge, 1969, pp.23-24)

34 J.L. Austin, How to Do Things with Words, Oxford, 1962, p.94. 
